\title{
Optimal accumulation in an endogenous growth setting with human capital
}

F. Docquier, 0. Paddison and P. Pestieau

Discussion Paper 2006-22

\section{Département des Sciences Économiques de l'Université catholique de Louvain}




\title{
Optimal accumulation in an endogenous growth setting with human capital ${ }^{*}$
}

\author{
Frédéric Docquier ${ }^{a}$, Oliver Paddison ${ }^{b} \&$ Pierre Pestieau $^{c}$ \\ ${ }^{a}$ FNRS, IRES, Catholic University of Louvain and IZA-Bonn \\ ${ }^{b}$ ECLAC, United Nations Economic Commission for Latin America and the Caribbean \\ ${ }^{c}$ CREPP, University of Liège, CORE, PSE \& CEPR
}

May 2006

\begin{abstract}
${ }^{*}$ We are grateful to an anonymous referee and David De la Croix for their helpful comments. This research was initiated with Maurice Marchand and Philippe Michel. This paper presents research of the Belgian Program on Interuniversity Poles of Attraction initiated by the Belgian State, Prime Minister's Office, Science Policy Programming. The scientific responsibility is assumed by the authors. Correspondence: Frédéric Docquier, Université Catholique de Louvain, IRES Department of Economics, 3 Place Montesquieu, B-1348 Louvain-La-Neuve, Belgium. Email: docquier@ires.ucl.ac.be. Phone: (+32)10.47.41.49. Fax: $(+32) 10.47 .39 .45$.
\end{abstract}




\begin{abstract}
This paper considers a three-overlapping-generations model of endogeneous growth wherein human capital is the engine of growth. It first contrasts the laissez-faire and the optimal solutions. Three possible accumulation regimes are distinguished. Then it discusses a standard set of tax-transfer instruments that allow for decentralization of the social optimum. Within the limits of our model, the rationale for the standard pattern of intergenerational transfers (the working-aged financing the education of the young and the pension of the old) is seriously questioned. On pure efficiency grounds, the case for generous public pensions is rather weak.
\end{abstract}

Keywords: endogenous growth, human capital, intergenerational transfers.

JEL classification: D90, H21, H52 


\section{Introduction}

Since Diamond [9], it is well known that the laissez-faire capital accumulation path needs not be dynamically efficient in the overlapping generations economy with selfish agents. In case of overaccumulation, intergenerational arrangements can be used to increase the welfare of all (present and future) generations. The golden rule steady state defines the frontier of Pareto efficient solutions. However, such a golden rule is hard to transpose to growing economies where consumer expenditures are increasing over time. Introducing a social welfare function is useful to discriminate among all efficient solutions. On the balanced growth path, the modified golden rule applies.

The problem is more complex when the rate of growth is endogenous. Suppose human capital is the engine of growth. Then, two sources of inefficiency are likely to interact. First, for a given social rate of time preference, individual saving decisions do not generate the appropriate amount of physical capital accumulation. Second, educational investments tend to be insufficient because the private value of human capital is lower than its social value by the positive externality it exerts on future generations. In this paper we analyze the optimal path of accumulation in such an endogenous growth setting and compare it to the market allocation. We then turn to policy issues and investigate the role of intergenerational transfers. The case for generous public pensions and education subsidies is seriously questionned.

Our endogenous framework is approporiate to assess the role of the intergenerational transfers. The new growth literature has stressed the role of human capital on sustained growth (see Lucas [13], Romer [15], Barro, Mankiw, and Sala-I-Martin [2]). Despite discouraging empirical results obtained in the 1990s (data sets used in the 1990s reveal a number of suspicious features and inconsistencies), recent empirical studies find a clear positive correlation between human capital and growth (see Cohen and Soto [5], De la Fuente and Domenech [8], Coulombe and Tremblay [6]) ${ }^{1}$. This empirical literature leaves intact the critical issue of why and how human capital is (or should be) accumulated. Abstracting from considerations of myopia, liquidity constraints and redistribution, we build a three-overlapping-generations model of endogenous growth which explains education and saving decisions. As in Michel [14], De la Croix and Michel [7] and more recently Boldrin and Montes [3,4], agents live for three periods. In the first, they incur some education cost which is financed by borrowing on the financial market. In the second period, they work with their labor supply being fixed and their wage depending on their educational investment and also on the overall level of human capital. Their earnings are used to finance current consumption, refund the amount borrowed for their education and save for retirement. In the third period, they retire. Contrary to the above studies, the current paper uses very general production and utility functions. ${ }^{2}$ Focusing on balanced growth

\footnotetext{
${ }^{1}$ Cohen and Soto [5] obtain a 8.5 percent rate of return on education (to be compared with 4.6 percent for physical capital) which is fairly compatible with the Mincerian microeconomic literature.

${ }^{2}$ Azariadis and Drazen [1] develop a model in the same vein but with human capital produced
} 
solutions, we demonstrate that three regimes can be observed. On the one hand, the market amount of capital per worker can be higher or lower than the optimal amount (overaccumulation or underaccumulation of physical capital). On the other hand, the laissez-faire growth rate can be lower or higher than the optimal growth rate (underaccumulation or overaccumulation of human capital). The educational externality induces two major consequences: (i) the case with overaccumulation of human capital and underaccumulation of physical capital cannot be observed, and (ii) the optimal solution will never be reached in the market economy.

Regarding decentralization, we investigate how education subsidies and intergenerational transfers can be used to restore optimality. It seems surprising that there have been few attemps to combine these two important aspects of the intergenerational state in a unified framework. Docquier and Michel [10] introduce public pensions and education subsidies in a setting with two types of human capital investments (education expenditures and time spent at school). Investigating various policy adjustments in the presence of demographic shocks, they essentially rely on numerical simulations. In a similar context, Docquier and Paddison [11] consider heterogeneous agents and simulate the growth and inequality effects of social security benefit rules. Glomm and Kaganovich [12] measure the growth and distributive effects of increased spending on public education that comes at a cost of decreased pension benefits. Turning to empirical works, Zhang [16] or Zhang and Zhang [17] estimate the impact of social security on growth.

These studies essentially adopt a positive approach. A step towards a normative view is provided in Boldrin and Montes [3,4]. They show that mixing social security and public education programs corrects allocational inefficiencies. They build a model in which the absence of credit market impedes young generations to accumulate productive human capital. The welfare state is then justified by the inability of decentralized markets to deliver a Pareto efficient solution. Combining public education and ascending transfers is required to restore the complete market allocation. Nevertheless, the definition of "optimality" in the Boldrin-Montes framework is rather restrictive. Decentralizing the complete market allocation, they disregard the spillover effects associated with education decisions. On the contrary, our analysis assumes perfect credit markets and focuses on the social desirability of the laissezfaire allocation. We compare the market and the first best outcomes and show that a mix of education subsidies and intergenerational transfers can be used to reach optimality. Interestingly, we demonstrate that there is no reason for the government to provide retired workers with public pension benefits when the social discount rate is sufficiently low (i.e. when the social weight given to future generations is high). To illustrate this result, we calibrate a computable version of our general model so as to match realistic interest rates and growth rates on the balanced growth path. For realistic private and social discount rates, taxing retirees is usually required to achieve the right amount of physical and human capital accumulation. On pure efficiency

out of forgone labor. 
grounds, the case for generous public pensions is rather weak.

The remainder of this paper is organized as follows. In Section 2, we begin our analysis with the comparison between the laissez-faire equilibrium and the social optimum. We investigate in Section 3 under which conditions the first-best can be decentralized with a subsidy on education and lump-sum transfers in both the second and the third period. Section 4 concludes.

\section{Laissez-faire vs. first best}

Individuals live for three periods: they invest in education in the first period, work in the second one and retire in the third one. The generation at work in period $t$, which is thus born in period $t-1$, is indexed by $t$. The size of generation $t$ is given by $N_{t}=(1+n) N_{t-1}$, where $n$ is the constant rate of population growth. In period $t$ the population size is thus $N_{t-1}+N_{t}+N_{t+1} \cdot{ }^{3}$

An individual of generation $t$ invests in education an amount $e_{t-1}$ in period $t-1$. This results in a level of (per capita) human capital or effective labor supply that is given by $h_{t}=\Phi\left(e_{t-1}, h_{t-1}\right)$ where $h_{t-1}$ is the level of human capital inherited from parents. Function $\Phi$ is assumed to be homogeneous of degree 1 in its two arguments. Therefore, we can write it in intensive form as:

$$
h_{t}=h_{t-1} \Phi\left(\frac{e_{t-1}}{h_{t-1}}, 1\right) \equiv h_{t-1} \varphi\left(\bar{e}_{t-1}\right) \quad \text { with } \bar{e}_{t-1} \equiv \frac{e_{t-1}}{h_{t-1}}
$$

where $\varphi(\bar{e})$ is positive, increasing and strictly concave, and satisfies the Inada conditions: $\varphi^{\prime}(0)=\infty$ and $\varphi^{\prime}(\infty)=0$.

With $c_{t}$ and $d_{t+1}$ denoting consumption in the first and second periods respectively, the preferences of generation- $t$ individuals are represented by the following utility function:

$$
u_{t}=u\left(c_{t}, d_{t+1}\right)
$$

This function is strictly increasing, strictly concave and homogeneous of degree $b$ in its two arguments. ${ }^{4}$ It also verifies the following Inada conditions: $u_{c}(0, d)=\infty$ and $u_{d}(c, 0)=\infty$.

The production side is represented by an aggregate production function relating output $Y_{t}$ in period $t$ to the physical capital, $K_{t}$, and the aggregate human capital or effective labor supply, $H_{t}=N_{t} h_{t}$, that are available in period $t$. This function is given

\footnotetext{
${ }^{3}$ Formally, our model is one of three overlapping generations. However, in the first period of life, children depend on their parents for consumption. Their only decision concerns education. Henceforth, consumption in childhood does not appear in individual utility functions and there is no room for substitution to the benefit or at the expense of this first period of life.

${ }^{4}$ When $b<1$, indifference curves are homothetic in the $(c, d)$-space. Note that any ordinal homogeneous utility function can be changed in a degree- $b$ homogeneous function by using an appropriated monotonic increasing transformation.
} 
by $Y_{t}=F\left(K_{t}, H_{t}\right)$, which is assumed to be homogeneous of degree 1 . Therefore, we can also write:

$$
Y_{t}=H_{t} f\left(\bar{k}_{t}\right) \quad \text { with } \bar{k}_{t} \equiv \frac{K_{t}}{H_{t}}
$$

where $f(\bar{k})$ is assumed to be positive, strictly increasing and strictly concave in $\bar{k}$, i.e. the ratio of physical capital to human capital. ${ }^{5}$

\subsection{Laissez-faire equilibrium}

We assume a perfect credit market. Individuals of generation $t$ borrow $e_{t-1}$ when they get educated in $t-1$ and reimburse $R_{t} e_{t-1}$ when they work in $t$, with $R_{t}=1+r_{t}$ being the interest factor. With $w_{t}$ denoting the wage rate per unit of effective labor, their net income in period $t$ is therefore:

$$
W_{t}=w_{t} h_{t}-R_{t} e_{t-1}=h_{t-1}\left(w_{t} \varphi\left(\bar{e}_{t-1}\right)-R_{t} \bar{e}_{t-1}\right) .
$$

Individuals use this net income for current consumption $c_{t}$ and saving $s_{t}$ so that when retired they consume

$$
d_{t+1}=R_{t+1} s_{t} .
$$

They choose $\bar{e}_{t-1}$ and $s_{t}$ so as to maximize their utility:

$$
u\left(c_{t}, d_{t+1}\right)=u\left(h_{t-1}\left(w_{t} \varphi\left(\bar{e}_{t-1}\right)-R_{t} \bar{e}_{t-1}\right)-s_{t}, R_{t+1} s_{t}\right) .
$$

The optimal choice of education by an individual of generation $t$ is thus given by:

$$
\varphi^{\prime}\left(\bar{e}_{t-1}\right)=\frac{R_{t}}{w_{t}}
$$

while his optimal choice of saving satisfies:

$$
u_{c}\left(c_{t}, d_{t+1}\right)=R_{t+1} u_{d}\left(c_{t}, d_{t+1}\right) .
$$

The above two conditions together yield the demand function for education and first- and second-period consumptions: $e_{t-1}\left(R_{t}, w_{t}, h_{t-1}\right), c_{t}\left(R_{t}, R_{t+1}, w_{t}, h_{t-1}\right)$ and $d_{t+1}\left(R_{t}, R_{t+1}, w_{t}, h_{t-1}\right)$ in the laissez-faire economy. Then, using (6) the net income of an individual of generation $t$ is:

$$
W_{t}=h_{t-1} w_{t}\left[\varphi\left(\bar{e}_{t-1}\right)-\varphi^{\prime}\left(\bar{e}_{t-1}\right) \bar{e}_{t-1}\right]
$$

in which the expression in brackets is positive since the strict concavity of $\varphi(\bar{e})$ implies that $\varphi(\bar{e})-\bar{e} \varphi^{\prime}(\bar{e})>\varphi(0) \geq 0$. Using (1), relation (8) can also be written as:

$$
W_{t}=h_{t} w_{t}\left[1-\lambda\left(\varphi\left(\bar{e}_{t-1}\right)\right)\right]
$$

\footnotetext{
${ }^{5}$ In Michel [14], the utility function is loglinear and both production and human capital functions are Cobb-Douglas.
} 
where the elasticity $\lambda\left(\varphi\left(\bar{e}_{t-1}\right)\right)$ is defined as:

$$
\lambda(\varphi(\bar{e}))=\frac{\bar{e} \varphi^{\prime}(\bar{e})}{\varphi(\bar{e})}<1 .
$$

In competitive markets the remuneration of production factors is equal to their marginal product:

$$
\begin{aligned}
& R_{t}=f^{\prime}\left(\bar{k}_{t}\right) \equiv R\left(\bar{k}_{t}\right), \\
& w_{t}=f\left(\bar{k}_{t}\right)-\bar{k}_{t} f^{\prime}\left(\bar{k}_{t}\right) \equiv w\left(\bar{k}_{t}\right),
\end{aligned}
$$

where $R\left(\bar{k}_{t}\right)$ is decreasing and $w\left(\bar{k}_{t}\right)$ is increasing in $\bar{k}_{t}$. Plugging (10) and (11) into (6) yields:

$$
\bar{e}_{t-1}=\varphi^{\prime-1}\left(\frac{R\left(\bar{k}_{t}\right)}{w\left(\bar{k}_{t}\right)}\right) \equiv \bar{e}\left(\bar{k}_{t}\right)
$$

with $\bar{e}\left(\bar{k}_{t}\right)$ increasing in $\bar{k}_{t}$. Using this result the net income $W_{t}$ in (9) can be written as:

$$
W_{t}=h_{t} \psi\left(\bar{k}_{t}\right)
$$

where

$$
\psi\left(\bar{k}_{t}\right) \equiv w\left(\bar{k}_{t}\right)\left[1-\lambda\left(\varphi\left(\bar{e}\left(\bar{k}_{t}\right)\right)\right]>0 .\right.
$$

Our assumption that the utility function is homogeneous in $c_{t}$ and $d_{t+1}$ (i.e. indifference curves are homothetic) makes saving proportional to net income. In other words the saving rate that we denote by $s$ depends only on the interest factor $R_{t}$ :

$$
s_{t}=s\left(R_{t+1}\right) W_{t}=s\left(R_{t+1}\left(\bar{k}_{t+1}\right)\right) h_{t} \psi\left(\bar{k}_{t}\right) .
$$

The clearing condition in the financial market, $N_{t} s_{t}=K_{t+1}+N_{t+1} e_{t}$, can be written as:

$$
s_{t}=(1+n) \bar{k}_{t+1} h_{t+1}+(1+n) h_{t} \bar{e}_{t} .
$$

Using (1), (12) and (14), this market-clearing condition is equivalent to:

$$
\psi\left(\bar{k}_{t}\right)=\chi\left(\bar{k}_{t+1}\right)
$$

with

$$
\chi\left(\bar{k}_{t+1}\right) \equiv \frac{1+n}{s\left(R\left(\bar{k}_{t+1}\right)\right)}\left[\bar{k}_{t+1} \varphi\left(\bar{e}\left(\bar{k}_{t+1}\right)\right)+\bar{e}\left(\bar{k}_{t+1}\right)\right] .
$$

If $\psi$ and $\chi$ are both increasing functions, the dynamic path of $\bar{k}_{t}$ as defined by (15) is monotonic, and $\bar{k}_{t}$ converges towards a steady-state value which is denoted by $\bar{k}^{L F} \cdot{ }^{6}$ One then obtains a balanced growth path along which the variables chosen by individuals $\left(s_{t}, e_{t-1}, c_{t}\right.$ and $\left.d_{t+1}\right)$ grow at the same rate as individual human capital: $1+g^{L F}=h_{t+1} / h_{t}=\varphi\left(\bar{e}^{L F}\right)$ with $\bar{e}^{L F}=\bar{e}\left(\bar{k}^{L F}\right)$.

\footnotetext{
${ }^{6}$ The monotonic sequence $\bar{k}_{t}$ is bounded above because the limit of $\psi(\bar{k}) / \chi(\bar{k})$ when $\bar{k}$ tends to $\infty$ is equal to zero.
} 


\subsection{Social optimum}

To characterize the first-best social optimum we use as objective of the social planner the sum of lifetime utilities over generations discounted by a factor $\gamma(0<\gamma<1)$ reflecting social time preferences. This maximization is subject to the human capital equation (1) and to the following resource constraint

$$
h_{t} f\left(k_{t} / h_{t}\right)=c_{t}+\frac{d_{t}}{1+n}+(1+n) e_{t}+(1+n) k_{t+1}
$$

where $k_{t}=K_{t} / N_{t}$ is physical capital per worker. Notice that $\bar{k}_{t}=k_{t} / h_{t}$.

The Lagrangean expression can be written as:

$$
\begin{aligned}
£ \equiv & \sum_{t=0}^{\infty} \gamma^{t}\left\{u\left(c_{t}, d_{t+1}\right)+q_{t}\left[h_{t} f\left(k_{t} / h_{t}\right)-c_{t}-\frac{d_{t}}{1+n}\right.\right. \\
& \left.\left.-(1+n)\left(e_{t}+k_{t+1}\right)\right]+p_{t}\left[h_{t} \varphi\left(e_{t} / h_{t}\right)-h_{t+1}\right]\right\}
\end{aligned}
$$

where $\gamma^{t} q_{t}$ and $\gamma^{t} p_{t}$ are the multipliers associated with the resource constraint and the human capital equation respectively. Maximizing the above Lagrangean with respect to $c_{t}, d_{t}, e_{t}, k_{t+1}$ and $h_{t+1}$ yields:

$$
\begin{aligned}
& u_{c}\left(c_{t}, d_{t+1}\right)=q_{t} \quad \text { and } \quad u_{d}\left(c_{t-1}, d_{t}\right)=\frac{\gamma q_{t}}{1+n}, \\
& p_{t} \varphi^{\prime}\left(\bar{e}_{t}\right)=q_{t}(1+n), \\
& q_{t}(1+n)=\gamma q_{t+1} f^{\prime}\left(\bar{k}_{t+1}\right), \\
& p_{t}=\gamma q_{t+1}\left[f\left(\bar{k}_{t+1}\right)-\bar{k}_{t+1} f^{\prime}\left(\bar{k}_{t+1}\right)\right]+\gamma p_{t+1}\left[\varphi\left(\bar{e}_{t+1}\right)-\bar{e}_{t+1} \varphi^{\prime}\left(\bar{e}_{t+1}\right)\right],
\end{aligned}
$$

together with the transversality condition:

$$
\lim _{t \rightarrow \infty} \gamma^{t}\left(q_{t} \bar{k}_{t+1}+p_{t}\right) h_{t+1}=0
$$

Those conditions are sufficient since the problem is concave.

Eliminating the multipliers from the above conditions first yields:

$$
\frac{u_{c}\left(c_{t}, d_{t+1}\right)}{u_{d}\left(c_{t}, d_{t+1}\right)}=f^{\prime}\left(\bar{k}_{t+1}\right)
$$

which is satisfied in the competitive laissez-faire equilibrium as it can be inferred from (7) and (10). Next we obtain:

$$
\frac{u_{d}\left(c_{t-1}, d_{t}\right)}{u_{d}\left(c_{t}, d_{t+1}\right)}=\frac{\gamma f^{\prime}\left(\bar{k}_{t+1}\right)}{1+n} .
$$

This condition determines the optimal accumulation of physical capital. 
We also obtain from the first-order conditions for a maximum of (17):

$$
w\left(\bar{k}_{t+1}\right) \varphi^{\prime}\left(\bar{e}_{t}\right)=f^{\prime}\left(\bar{k}_{t+1}\right)-(1+n) \varphi^{\prime}\left(\bar{e}_{t}\right) \frac{\varphi\left(\bar{e}_{t+1}\right)-\bar{e}_{t+1} \varphi^{\prime}\left(\bar{e}_{t+1}\right)}{\varphi^{\prime}\left(\bar{e}_{t+1}\right)},
$$

which yields the optimal accumulation of human capital.

We have:

Definition 1 For a given rate of social time preference $\gamma$ and for initial conditions $\left(e_{-1}, s_{-1}, k_{0}, h_{0}, w_{0}, R_{0}\right)$ the optimal path $\left(c_{t}^{*}, d_{t}^{*}, e_{t}^{*}, h_{t}^{*}, k_{t}^{*}\right)$ satisfies the set of conditions (1), (16), (18), (19) and (20) for all $t \geq 0$.

It is straightforward to infer from (6), (10) and (11) that condition (20) is not satisfied in the competitive laissez-faire equilibrium. When choosing their investment on education, individuals ignore the intergenerational externality, represented by the second term on the right-hand side of (20). Their investment does not only affect their own income but also that of their children through the inherited human capital. Accordingly the investment on education is socially too low at the laissez-faire equilibrium, which is a well known feature of this sort of model. Another way to express this point is to rewrite (20) as:

$$
w\left(\bar{k}_{t+1}\right) \varphi^{\prime}\left(\bar{e}_{t}\right)=f^{\prime}\left(\bar{k}_{t+1}\right)\left(1-\Delta_{t+1}\right)
$$

where the educational externality is expressed as some fraction of the education cost, denoted by $\Delta_{t+1}$. In the next section where policies for decentralizing the social optimum are investigated, this fraction will define the government's implicit subsidy to education.

Finally, the transversality condition can be written as:

$$
\lim _{t \rightarrow \infty} \gamma^{t} u_{c}\left(c_{t}, d_{t+1}\right) h_{t+1}\left(\bar{k}_{t+1}+\frac{1+n}{\varphi^{\prime}\left(\bar{e}_{t}\right)}\right)=0 .
$$

Along a balanced growth path, the per-unit-of-effective-labor variables are constant, $\bar{e}_{t}=\bar{e}$ and $\bar{k}_{t}=\bar{k}$, while the per-capita variables $c_{t}, d_{t}$ and $h_{t}$ are growing at the constant rate $g$ defined by $1+g=\varphi(\bar{e})$ (as it can be inferred from (1)).

Since $u\left(c_{t}, d_{t+1}\right)$ is assumed to be homogeneous of degree $b<1, u_{c}\left(c_{t}, d_{t+1}\right)$ and $u_{d}\left(c_{t}, d_{t+1}\right)$ are homogeneous of degree $b-1$, which implies that $u_{d}\left(c_{t-1}, d_{t}\right) / u_{d}\left(c_{t}, d_{t+1}\right)=$ $[\varphi(\bar{e})]^{1-b}$. From (19) we then have:

$$
\frac{\gamma f^{\prime}(\bar{k})}{1+n}=[\varphi(\bar{e})]^{1-b}=(1+g)^{1-b}
$$

along the balanced-growth path. This is the analogue of Diamond'2 [9] modified golden rule in our endogenous growth model. It is important to note that along the balanced-growth path the growth factor of the expression on the left-hand side 
of $(22)$ is $\gamma[\varphi(\bar{e})]^{b}$, hence the transversality condition, given in $(22)$, is equivalent to $\gamma[\varphi(\bar{e})]^{b}<1$.

In Appendix A we prove the following proposition that states how the socially optimal values of $\bar{k}$ and $\bar{e}$ are related to the generational discount factor $\gamma$. In this proposition, $\gamma_{\max }$ denotes the upper bound of $\gamma$ for which the transversality condition holds.

Proposition 1 The long-run socially optimal values of $\bar{k}$ and $\bar{e}$ are increasing with $\gamma$ on the interval $\left(0, \gamma_{\max }\right)$ and both tend to 0 when $\gamma$ tends to 0.

In the rest of this section we investigate how the laissez-faire equilibrium compares with the social optimum according to $\gamma$. Let us first recall that in Diamond's [9] model of exogenous growth when underaccumulation prevails in the laissez-faire equilibrium, the capital-labour ratio corresponds to its socially optimal level for some $\gamma$ (i.e. the modified golden rule is verified). The present context is more complex since both the levels of human and physical capital are involved in the comparison. It is however immediate that along a balanced-growth path we cannot expect a result equivalent to that obtained in Diamond's model. For a given $\bar{k}$, the presence of the intergenerational externality mentioned above will always make the laissez-faire level of $\bar{e}$ differ from the social optimum.

In Appendix B we prove the following proposition in which subscripts $L F$ and $\star$ respectively indicate laissez-faire and socially optimal values. Let $\bar{k}_{\max }^{*}$ denote the limit of $\bar{k}^{*}(\gamma)$ when $\gamma$ tends to $\gamma_{\max }$.

Proposition 2 Consider a balanced-growth path in the laissez-faire economy which satisfies $\bar{k}^{L F}<\bar{k}_{\max }^{*}$. Then, there are two discount factors $\tilde{\gamma}$ and $\hat{\gamma}, 0<\tilde{\gamma}<\hat{\gamma}<\gamma_{\max }$ such that $\bar{k}^{*}(\hat{\gamma})=\bar{k}^{L F}$ and $\bar{e}^{*}(\tilde{\gamma})=\bar{e}^{L F}$. For $\gamma<\tilde{\gamma}$, both the levels of $\bar{k}^{*}(\gamma)$ and $\bar{e}^{*}(\gamma)$ are lower than $\bar{k}^{L F}$ and $\bar{e}^{L F}$ respectively; for $\gamma>\hat{\gamma}$, they are both higher; and for $\tilde{\gamma}<\gamma<\hat{\gamma}$, we have $\bar{e}^{*}(\gamma)>\bar{e}^{L F}$ and $\bar{k}^{*}(\gamma)<\bar{k}^{L F}$.

The results of these Propositions 1 and 2 are depicted in the following figure where the curve is the locus of the socially optimal combinations of $\bar{k}$ and $\bar{e}$ for values of $\gamma$ in the interval $\left(0, \gamma_{\max }\right)$ and point $L F$ represents the combination of $\bar{k}$ and $\bar{e}$ at the laissez-faire equilibrium. By definition the socially optimal combination for $\gamma=\hat{\gamma}$ (and for $\gamma=\tilde{\gamma}$ ) is located at the vertical (and at the horizontal) of $L F$ on the curve. For $0 \leq \gamma \leq \tilde{\gamma}$ (Regime $I$ ) both $\bar{k}^{*}$ and $\bar{e}^{*}$ are below $\bar{k}^{L F}$ and $\bar{e}^{L F}$ while for $\hat{\gamma}<\gamma \leq \gamma_{\max }$ (Regime III) they are both above. For intermediary values of $\gamma(\tilde{\gamma}<\gamma<\hat{\gamma}$ in Regime $I I)$, physical capital accumulation at the laissez-faire equilibrium is higher than at the social optimum while the opposite is true for human capital accumulation.

These results deserve several remarks. First, proposition 1 clearly shows that the competitive growth rate need not be lower than the first best rate despite spillover 
effects. When the social discount factor is low (Regime 1), a laissez-faire economy generates too much growth. Second, the critical thresholds $\tilde{\gamma}$ and $\hat{\gamma}$ are clearly dependent on the other parameters. For example, as the private rate of time preference decreases (i.e. as $\beta$ increases), individuals tend to save more. This pushes the interest rate downward and stimulates the investment in human capital. Since both physical and human capital accumulation increase with $\gamma$ at the first best, both $\tilde{\gamma}$ and $\hat{\gamma}$ increase. Finally, it ought to be stressed that if for a given $\gamma$ either $\bar{k}$ or $\bar{e}$ is set at a value different from its optimal value, it is not desirable to fix the other variable at its optimal value on the curve. This is an application of the standard second-best argument. 
Figure 1. Optimal level of human capital and physical capital as function of $\gamma$

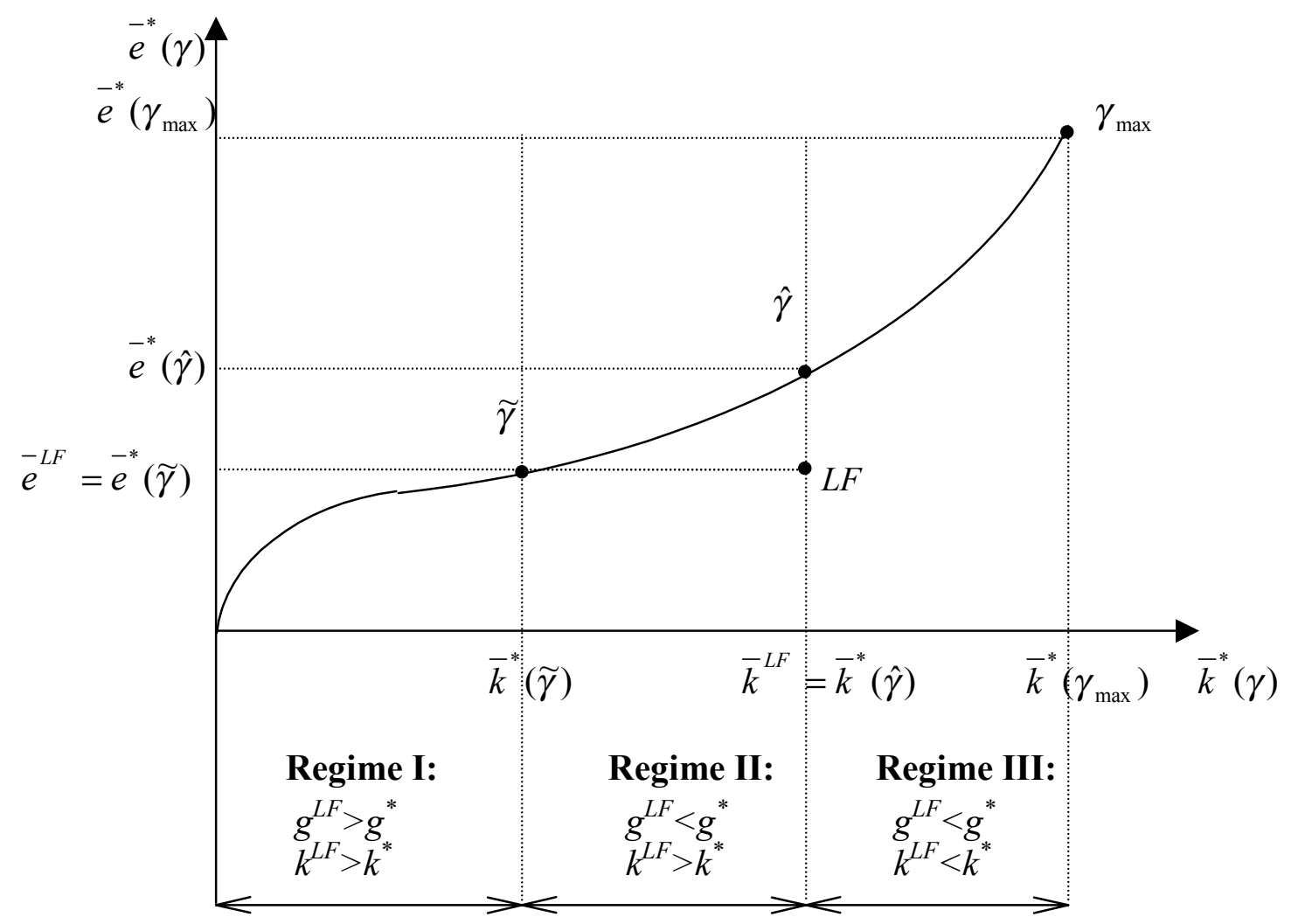




\section{$3 \quad$ Policy issues}

In the exogenous-growth model the social optimum can be achieved by means of appropriate transfers between generations. This insures that the accumulation of physical capital satisfying the modified golden rule is reached. The transfer is from the young to the old when the per-worker physical capital in the laissez-faire equilibrium is larger than that satisfying this rule, and in the opposite direction in the other case. In our endogenous-growth setting we need an additional instrument, namely an education subsidy or alternatively an earning subsidy. Various sets of instruments could be used to decentralized the optimal accumulation path. In the following we abstract from proportional labor income taxes, public debt/funds, VAT, wealth taxes and many other policy instruments. We restrict our analyis to the basic fiscal packages of intergenerational transfers. An individual born at time $t-1$ may face three taxes or transfers during his life span. Let $\sigma_{t-1}$ denote the rate of subsidy on educational spending, $T_{t}^{1}$ and $T_{t+1}^{2}$ the lump-sum taxes in the periods of work and of retirement. ${ }^{7}$ With these instruments, the budget constraints of the individual are:

$$
w_{t} h_{t}-R_{t}\left(1-\sigma_{t-1}\right) e_{t-1}-T_{t}^{1}=c_{t}+s_{t}
$$

and

$$
d_{t+1}=R_{t+1} s_{t}-T_{t+1}^{2} .
$$

Subject to these budget constraints where $h_{t}$ is substituted from $h_{t}=h_{t-1} \varphi\left(e_{t-1} / h_{t-1}\right)$ the utility function $u\left(c_{t}, d_{t+1}\right)$ is maximized with respect to $e_{t-1}$ and $s_{t}$, which yields the following first order conditions:

$$
w_{t} \varphi^{\prime}\left(\bar{e}_{t-1}\right)=R_{t}\left(1-\sigma_{t-1}\right)
$$

and

$$
u_{c}\left(c_{t}, d_{t+1}\right)=R_{t+1} u_{d}\left(c_{t}, d_{t+1}\right) .
$$

It is important to note that the subsidy $\sigma_{t-1}$ directly affects the accumulation of physical capital. At time $t$, the market-clearing condition for capital is

$$
(1+n) k_{t+1}=s_{t}-(1+n)\left(1-\sigma_{t}\right) e_{t} .
$$

The government revenue constraint including all tax instruments can be written as:

$$
T_{t}^{1}+\frac{T_{t}^{2}}{(1+n)}=(1+n) \sigma_{t} e_{t}
$$

Using the individual budget constraints and the Euler equation for the homogeneous production function, this can be shown to be equivalent to the resource constraint

$$
F\left(k_{t}, h_{t}\right)=c_{t}+\frac{d_{t}}{1+n}+(1+n) k_{t+1}+(1+n) e_{t}
$$

\footnotetext{
${ }^{7}$ In an earlier version of the paper, we examined alternative policy packages with proportional labor income taxes and a rate of subsidy on the reimbursement of the educational loan. We show that either one fiscal instrument is redundant. The results are available upon request.
} 
Our purpose is to investigate which values of policy instruments should be used in order to achieve a social optimum in a market economy. Following definition 1, the optimal values of the key variables $\left(c_{t}^{*}, d_{t}^{*}, e_{t}^{*}, h_{t}^{*}, k_{t}^{*}\right)$ satisfy conditions (1)-(16)(18)-(19)-(20). At a market equilibrium, where conditions (10) and (11) - according to which the prices of factors are equated to their marginal productivities - hold, conditions (1), (16) and (18) are automatically satisfied. The first of these conditions is taken into account in the individual's optimization problem, the second one is equivalent to the government budget constraint, and the third one is equivalent to (27). Therefore, it remains to satisfy conditions (19) and (20) by some proper choice of the policy instruments.

Condition (19) has to do with the accumulation of physical capital $\left(k_{t+1}^{*}\right)$. Let us denote by $s_{t}^{*}\left(\sigma_{t}\right)$ the saving required at time $t$ to achieve this optimal accumulation:

$$
s_{t}^{*}\left(\sigma_{t}\right)=(1+n) k_{t+1}^{*}+(1+n)\left(1-\sigma_{t}\right) e_{t}^{*} .
$$

As to condition (20), it concerns the optimal choice of education spending $\left(e_{t-1}^{*}\right)$. Accordingly, from (24), (25) and (26), the policy instruments need to be set so as to satisfy the three following conditions for $t \geq 1$ :

$$
\begin{aligned}
& \left(A_{t}\right) \quad T_{t}^{1}=w_{t}^{*} h_{t}^{*}-R_{t}^{*}\left(1-\sigma_{t-1}\right) e_{t-1}^{*}-c_{t}^{*}-s_{t}^{*}\left(\sigma_{t}\right) \\
& \left(B_{t}\right) \quad T_{t+1}^{2}=R_{t+1}^{*} s_{t}^{*}\left(\sigma_{t}\right)-d_{t+1}^{*} \\
& \left(C_{t}\right) \quad \Delta_{t}^{*}=\sigma_{t-1}
\end{aligned}
$$

where from $(21), \Delta_{t}^{*}$ is defined by:

$$
\left(1-\Delta_{t}^{*}\right) f^{\prime}\left(k_{t}^{*} / h_{t}^{*}\right)=w\left(k_{t}^{*} / h_{t}^{*}\right) \varphi^{\prime}\left(e_{t-1}^{*} / h_{t-1}^{*}\right)
$$

In $t=0$, given $e_{-1}, s_{-1}, k_{0}, h_{0}$ and hence $w_{0}$ and $R_{0}$, one has:

$$
\begin{aligned}
& \left(A_{0}\right) \quad T_{0}^{1}=w_{0} h_{0}-R_{0} e_{-1}-c_{0}^{*}-s_{0}^{*}\left(\sigma_{0}\right), \\
& \left(B_{0}\right) \quad T_{0}^{2}=R_{0} s_{-1}-d_{0}^{*} .
\end{aligned}
$$

This leads us to our next proposition on the decentralization of the social optimum.

Proposition 3 If the tax policy verifies conditions $\left(A_{t}\right)$ and $\left(B_{t}\right)$ for $t \geqslant 0$ and $\left(C_{t}\right)$ for $t \geqslant 1$ then the social optimum is a market equilibrium.

Formally, one sees that lump-sum taxes $T_{t}^{1}$ and $T_{t+1}^{2}$ can be used to fulfill $\left(A_{t}\right)$ and $\left(B_{t}\right)$ i.e. to achieve the optimal accumulation of physical capital. Then, to obtain condition $\left(C_{t}\right)$ one can use $\sigma_{t-1}=\Delta_{t}^{*}$. Given that $\Delta_{t}^{*}$ represents the fraction of educational cost that corresponds to the human capital externality, it is not surprising that it is equal to the rate of subsidy on education spending.

In Appendix $\mathrm{C}$ we study an analytical illustration of our model in which the following specification of our key functions is used: $u\left(c_{t}, d_{t+1}\right)=\ln c_{t}+\beta \ln d_{t+1}$, $\varphi\left(e_{t}\right)=B e_{t}^{\lambda}$ and $f\left(k_{t}\right)=A k_{t}^{\alpha}$, with $\beta>0, B>0,0<\lambda<1, A>0$ and 
$0<\alpha<1$. Our main purpose in this appendix is to investigate the properties of the optimal policies along balanced growth paths. We focus on the properties of the optimal policy. With the above specification, this policy is characterized using (C.6) in Appendix $\mathrm{C}$ by $\sigma=\gamma(1-\lambda)$, showing that the subsidy rate on education spending rises with the discount factor $\gamma$, which is consistent with the discussion above. As to the second-period lump-sum tax, it can be inferred from Appendix C using (C.15) and (C.16) where we substitute $\sigma=\gamma(1-\lambda)$ from (C.6) that $\bar{T}_{2}=T_{t}^{2} / h_{t}$ rises with $\gamma$. This is as expected by analogy to the exogenous-growth model: more concern given to future generations increases the required level of physical accumulation and therefore saving, which is achieved by increasing $T^{2}$ and decreasing $T^{1}$. However, in our endogenous-growth model there is no clear-cut result about the way $\bar{T}^{1} \equiv T_{t}^{1} / h_{t}$ changes as $\gamma$ rises (see (C.19) in Appendix C), this is because workers are subject to two fiscal instruments, $\sigma$ and $T^{1}$. Therefore, what matters is the aggregate tax liability of workers. It is also possible to show that with the above specification, there exists a critical value of $\gamma$, say $\overline{\bar{\gamma}}$, with $0<\overline{\bar{\gamma}}<1$, such that $\bar{T}^{2}$ is negative for $\gamma<\overline{\bar{\gamma}}$ and positive for $\gamma>\overline{\bar{\gamma}}$. So when $\gamma<\overline{\bar{\gamma}}, T^{2}$ can be interpreted as a pension benefit given to retirees.

To illustrate this result, let us assign a reasonable value to each parameter and provide a numerical computation of the balanced growth policy package $\left(\sigma_{t}, T_{t}^{1}, T_{t}^{2}\right) \cdot{ }^{8}$ Without loss of generality, the scale parameter $A$ is normalized to one (it determines the unit of measure). The share of capital income $(\alpha)$ is set to 0.25. Assume one period represents 20 years. We use $1+n=1.1$ (a 0.5 percent annual growth rate of the population). The parameter $\beta$ reasonably ranges from 0.67 (a 0.5 percent annual rate of time preference) to 0.90 (a 2 percent annual rate). A reasonable median value is $\beta=0.8$. The parameters of the training technology are calibrated in such a way that the laissez-faire interest rate and growth rate match target values. We fix $\beta=0.8$ and select $B$ and $\lambda$ so as to obtain a 2.5 percent annual interest rate $(R=1.64)$ and a 2 percent annual GDP growth rate $(G(1+n)=1.49)$ at the steady state. Using a backsolving method (i.e. swapping endogenous variables and parameters), we obtain $B=1.7249$ and $\lambda=0.1304$. For this set of parameters, simulation results are represented on Figure 2.

Figure 2.a generalizes proposition 2 in the plane $(\beta, \gamma)$. Vertically (i.e. for a given $\gamma)$, the critical value $\beta(1)$ defines the locus above which the market capital per worker exceeds the optimal amount $\left(\bar{k}_{s s}^{L F}>\bar{k}_{s s}^{*}\right)$. The critical value $\beta(2)$ defines the locus above which the market growth rate exceeds the optimal growth rate $\left(g_{s s}^{L F}>g_{s s}^{*}\right)$. Horizontally (i.e. for a given $\beta$ ), the critical curves are strictly equivalent to the thresholds $(\widetilde{\gamma}, \widehat{\gamma})$ discussed in proposition 2 and depicted on figure 1 . Obviously, for high $\beta$ and low $\gamma$, both capital per worker and education investments are higher in the laissez-faire economy (Regime 1). For high $\beta$ and high $\gamma$, the optimal growth rate exceeds the market rate while overaccumulation of physical capital still holds (Regime

${ }^{8}$ On the balanced growth, $\sigma_{t}, \frac{T_{t}^{1}}{w_{t} h_{t}}$ and $\frac{T_{t}^{2}}{w_{t} h_{t}}$ are constant over time. 
2). Finally, when $\beta$ is low and $\gamma$ is high, both capital per worker and education investments are higher at the social optimum (Regime 3 ).

Figure 2.b to 2.d depict the optimal balanced growth policy package, i.e. the package which decentralizes the first best solution. We let $\beta$ and $\gamma$ vary in the interval $[0.5 ; 1.0] .^{9}$ Not surprisingly, the optimal education subsidy rate is strongly increasing with the social discount factor (see figure 2.b). It ranges from 55 to 95 percent. A more striking result appears on figure 2.c which represents the optimal social security replacement ratio (the opposite of the lump-sum tax on retirees, as percent of the average wage rate: $\left.\frac{-T_{t}^{2}}{w_{t} h_{t}}\right)$. It shows that pensions are negative when the social discount rate is sufficiently low (i.e. when $\gamma$ is sufficiently high). For example, when $\beta=0.8$, pensions are negative for any $\gamma>0.75$. For reasonable weights given to future generations, the case for public pensions is weak. In a world without myopia, inequality and/or credit market imperfections, taxing the retirees is a relevant option to decentralize the optimal path of human and physical capitals. On figure 2.d, the optimal tax on adults $\left(\frac{T_{t}^{1}}{w_{t} h_{t}}\right)$ balances the budget constraint. As $\gamma$ increases, education expenditures rise and social security expenditures fall. The second effect is dominant at low $\gamma$ whilst the first one is the largest at high $\gamma$. The optimal tax is a U-shaped function of $\gamma$, globally increasing with $\beta$.

\footnotetext{
${ }^{9}$ Note that for high $\gamma$, the transversality condition can be violated. Graphically, we do not represent that transversality constraint.
} 
Figure 2. Numerical illustration

2.a. Competitive versus optimal accumulation

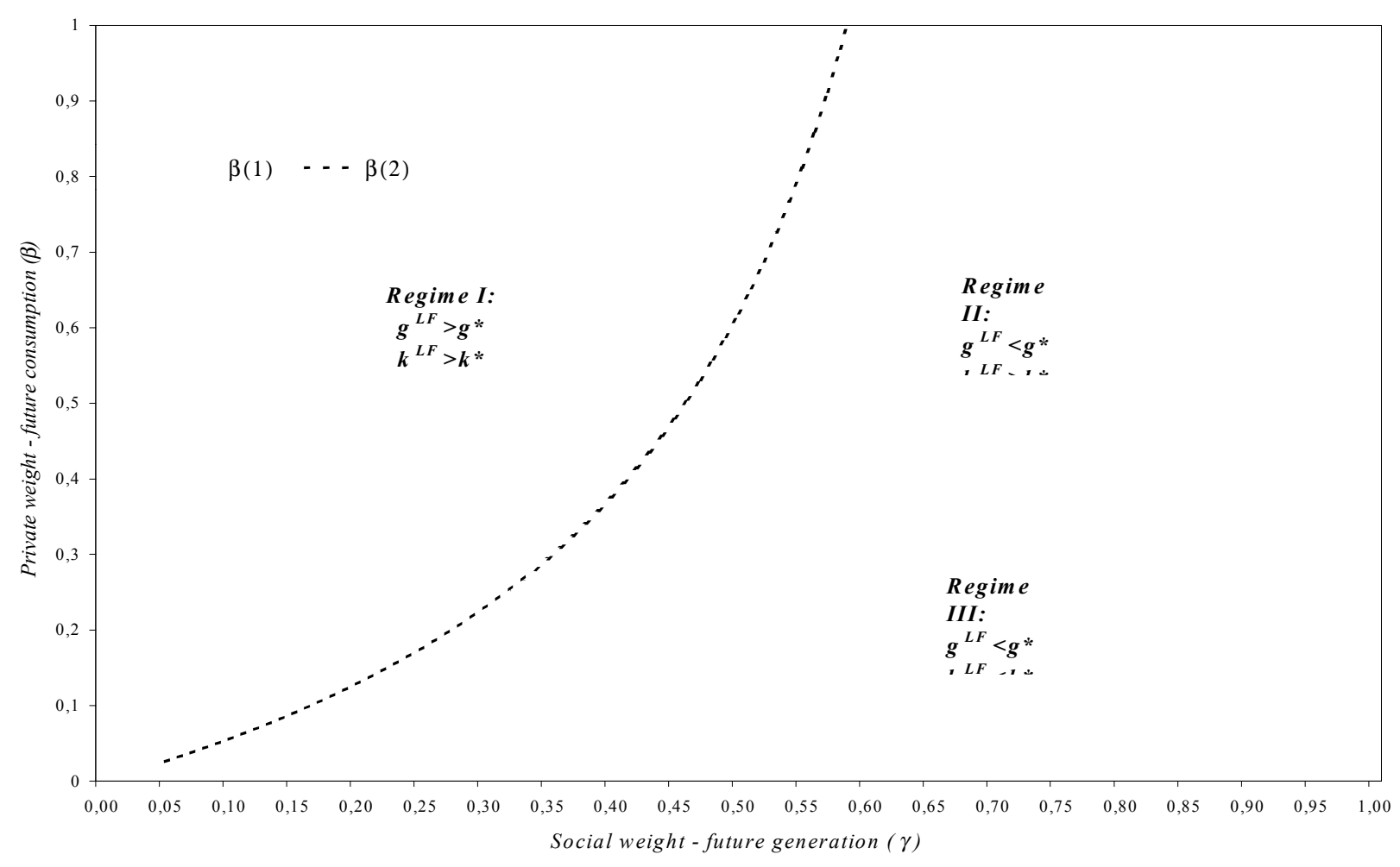

2.b. Subsidy rate on education expenditures (s)

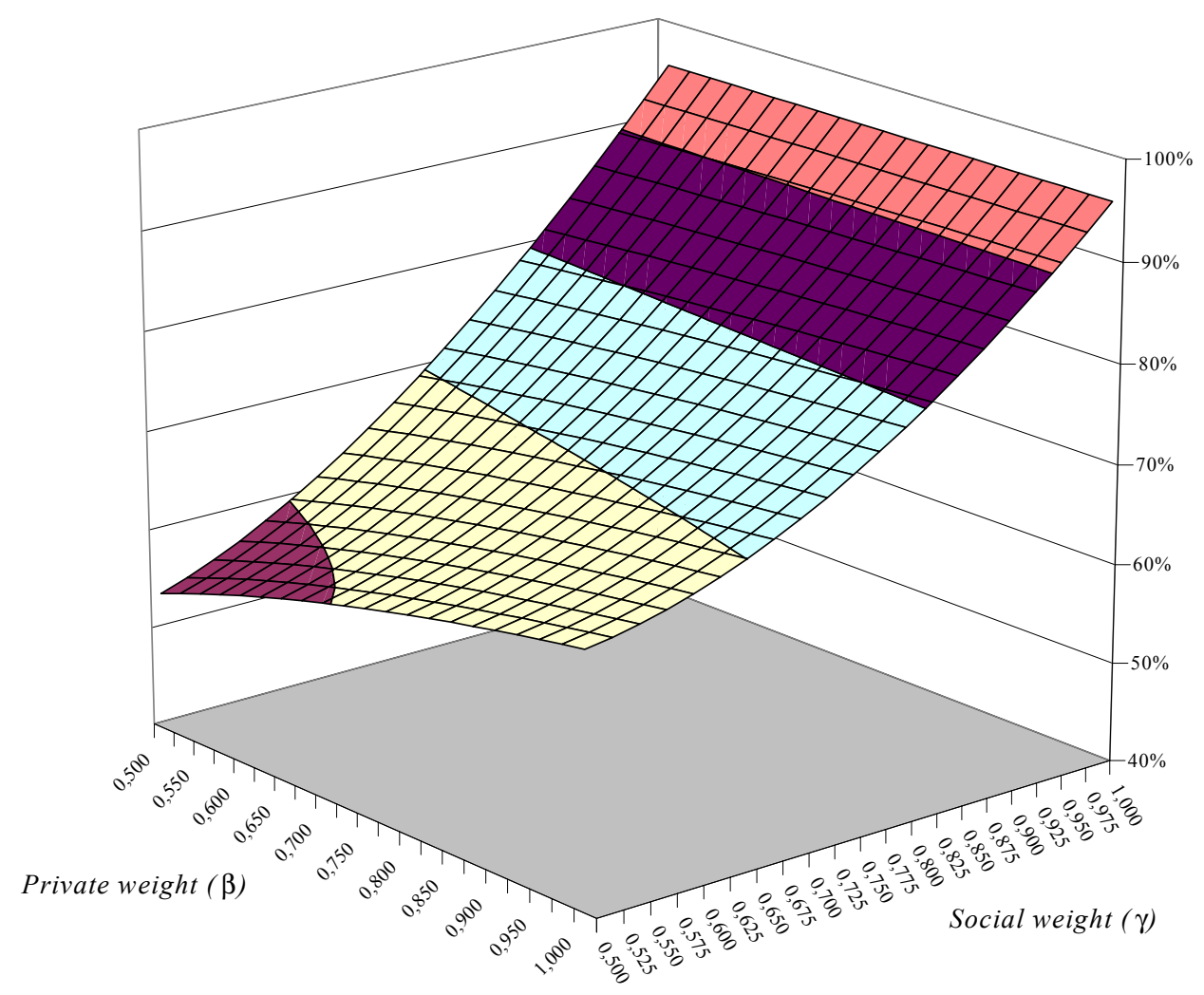


Figure 2. Numerical illustration (continued)

2.c. Public pension as percent of adult wage $\left(-T^{2} / w h\right)$

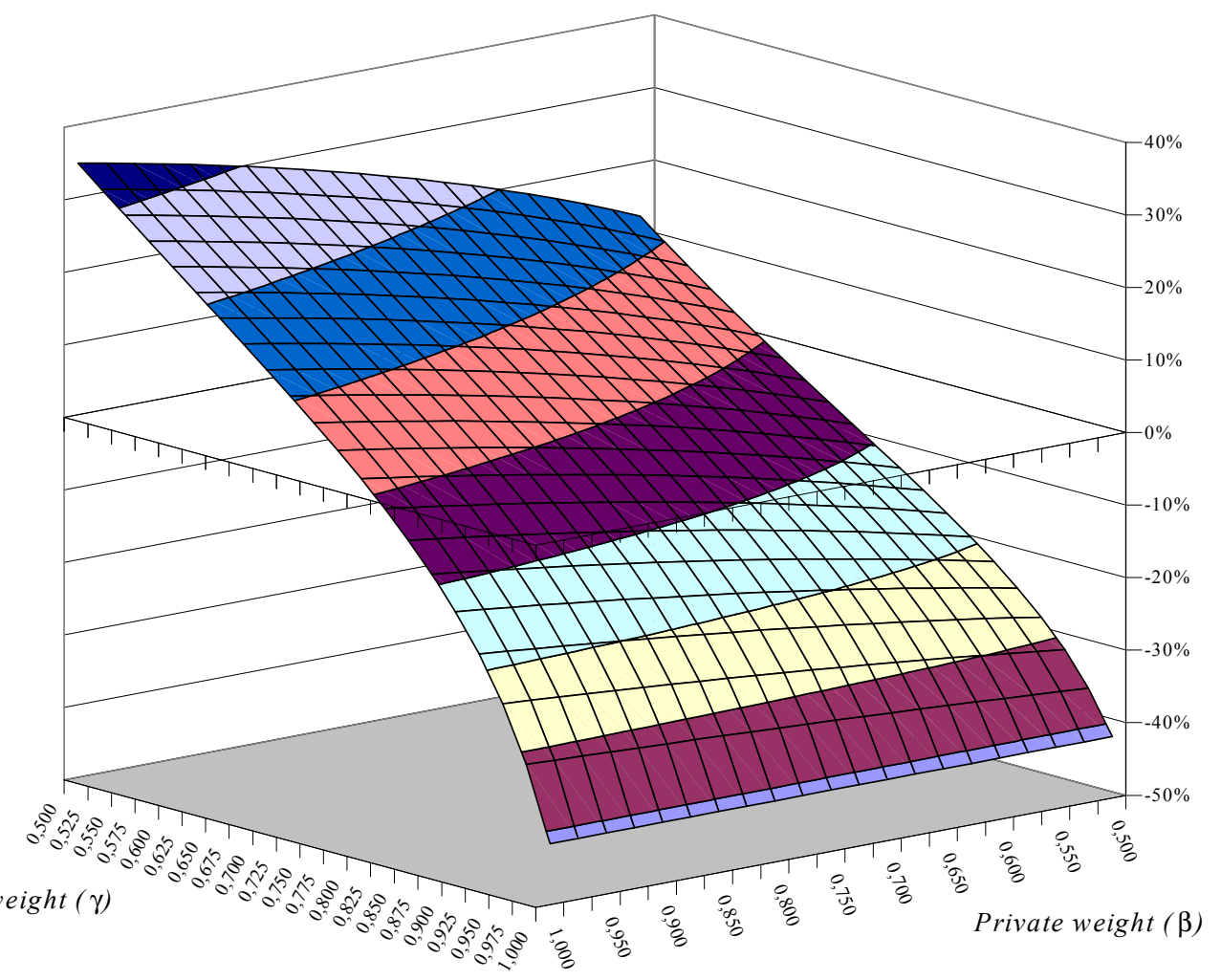

2.d. Lump-sum tax on adults (T1/wh)

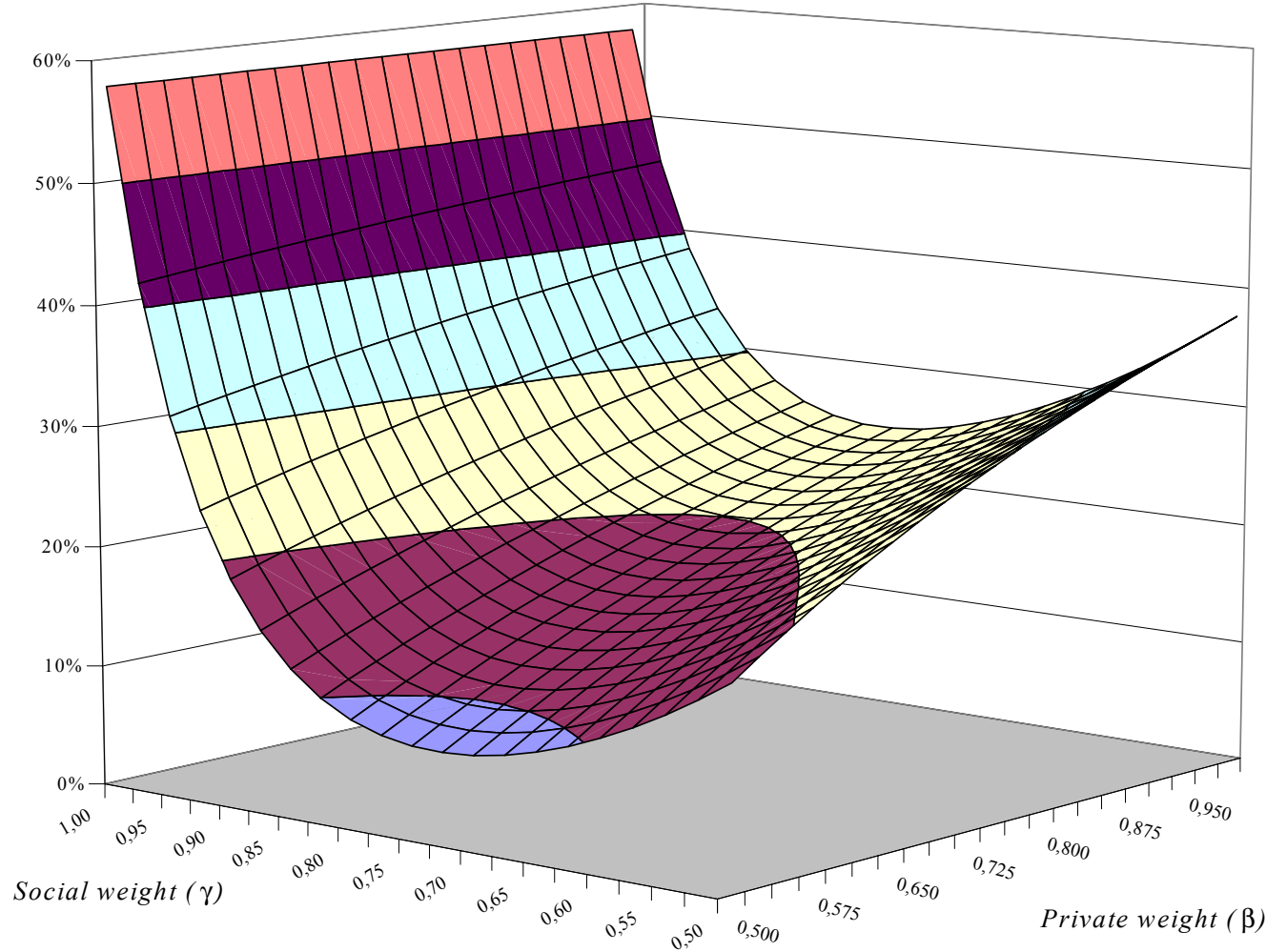




\section{Conclusion}

In overlapping generations models of exogenous growth the long-run level of capital accumulation at the laissez-faire equilibrium is easily compared to the one at the social optimum. If underaccumulation prevails in the former, capital-labor ratio is too low with respect to the modified golden rule. This occurs when the social discount rate is high. On the other hand, if overaccumulation prevails at the laissez-faire longrun equilibrium, this equilibrium is dynamically inefficient, which happens when the social discount rate is low. In both cases, the social optimum can be achieved by lump-sum intergenerational transfers.

However in our endogenous growth model with education the comparison between the laissez-faire equilibrium and the social optimum has to do with two variables, namely the capital-labor ratio and the education-human capital ratio. In the absence of altruism there is always underinvestment in education at the laissez-faire equilibrium because the impact on future generations of this investment is not internalized by individual decision makers. This paper combines physical and human capital accumulation issues. Since both stocks of capital increase with the social weight given to future generations, our model reveals that three regimes can be observed. When the social weight is low, there is overaccumulation of both physical and human capitals at the long-run competitive equilibrium. This means too much growth in the competitive economy. When the social weight is high, there is underaccumulation of both capitals. Intuitively, for intermediate values, there is overinvestment in physical capital and underinvestment in education at the long-run laissez-faire.

Decentralizing the social optimum requires standard intergenerational transfers (for adjusting saving decisions) as well as some subsidy to education (for adjusting education decisions). This subsidy internalizes the positive externality that an education investment exercises on future generations. Our package of intergenerational transfers comprises a tax-transfer to the retirees and a subsidy on education. With these instruments a first-best can be achieved but likely with a tax on the retirees, a tax on adults and a subsidy on educational spending. As the social weight given to future generations increases, the case for public pensions becomes weaker and weaker. In the introductory paragraph we questionned the rationale for the observed pattern of public transfers and taxes (the working generation financing the education of the young and the pension of the old). Within the limits of our model quite different patterns can result, even in a first-best framework. 


\section{$5 \quad$ References}

[1] Azariadis, C. and A. Drazen, Threshold externalities in economic development, Quarterly Journal of Economics, 105 (1990), 501-526.

[2] Barro R.J., N.G. Mankiw and X. Sala-I-Martin, Capital Mobility in Neoclassical Models of Growth, American Economic Review, 85 (1995), 103-115.

[3] Boldrin, M. and A. Montes, Assessing the efficiency of public education and pensions, Unpublished, 2004a.

[4] Boldrin, M. and A. Montes, The intergenerational state - education and pensions, Review of Economic Studies, 72 (2005), 651-664.

[5] Cohen, D. and M. Soto, Growth and Education - Good data, good results, CEPR Discussion Paper, N. 3025, 2001.

[6] Coulombe, S. and J-F. Tremblay, Literacy, Human Capital, and Growth, Ottawa University Working Papers, n. 0407E, 2004.

[7] De la Croix, D. and Ph. Michel, A Theory of Economic Growth: Dynamics and Policy in Overlapping Generations, Cambridge University Press, 2002.

[8] De la Fuente, A. and A. Domenech, Human Capital in Growth Regressions: How Much Difference Does Data Quality Make?, CEPR Discussion Paper, n. 2466, 2000 .

[9] Diamond, P, National debt is a neo-classical growth model. American Economic Review, 55 (1965), 1126-1250.

[10] Docquier, F. and Ph. Michel, Education subsidies, social security and growth: the implications of a demographic shock, Scandinavian Journal of Economics (1999), 101, 423-440.

[11] Docquier, F. and O. Paddison, Social security benefit rule, growth and inequality, Journal of Macroeconomics, 25 (2003), 47-71.

[12] Glomm, G. and M. Kaganovich, Income distribution effects of public education and social security in a growing economy, Unpublished, Michigan State University, 1999.

[13] Lucas, R.E., On the mechanics of economic development, Journal of Monetary Economics, 21 (1988), 3-42.

[14] Michel, Ph., Le modèle à générations imbriquées, un instrument d'analyse macroéconomique, Revue d'Economie Politique, 2 (1993), 191-220.

[15] Romer, P., Endogenous Technical Change, Journal of Political Economy, 98 (1990), S71-S102.

[16] Zhang, J., Social security and endogenous growth, Journal of Public Economics, 58 (1995), 185-216.

[17] Zhang, J. and J. Zhang, How does social security affect economic growth? Evidence from a cross-country analysis. Unpublished, Chinese University of Hong Kong, 2000. 


\section{Appendix A: Proof of Proposition 1}

From (22) we can write:

$$
\gamma[\varphi(\bar{e})]^{b}=(1+n) \varphi(\bar{e}) / f^{\prime}(\bar{k})
$$

and hence the transversality condition, $\gamma[\varphi(\bar{e})]^{b}<1$, is equivalent to:

$$
f^{\prime}(\bar{k})-(1+n) \varphi(\bar{e})>0 .
$$

We also have from (20):

$$
f^{\prime}(\bar{k})-(1+n) \varphi(\bar{e})=\varphi^{\prime}(\bar{e})\left(f(\bar{k})-\bar{k} f^{\prime}(\bar{k})-(1+n) \bar{e}\right)
$$

and thus the transversality condition is also equivalent to:

$$
f(\bar{k})-\bar{k} f^{\prime}(\bar{k})-(1+n) \bar{e}>0 .
$$

Total differentiation of (A.3) with respect to $\bar{k}$ and $\bar{e}$ yields:

$$
\frac{d \bar{k}}{d \bar{e}}=\frac{\varphi^{\prime \prime}(\bar{e})\left[f(\bar{k})-\bar{k} f^{\prime}(\bar{k})-(1+n) \bar{e}\right]}{f^{\prime \prime}(\bar{k})\left[\bar{k} \varphi^{\prime}(\bar{e})+1\right]},
$$

which is positive when the transversality condition is satisfied. This means that $\bar{k}(\gamma)$ and $\bar{e}(\gamma)$ vary in the same direction. On the other hand, differentiating (22) yields:

$$
f^{\prime}(\bar{k}) d \gamma+\gamma f^{\prime \prime}(\bar{k}) d \bar{k}-\mu d \bar{e}=0
$$

with $\mu=(1+n)(1-b)[\varphi(\bar{e})]^{-b} \varphi^{\prime}(\bar{e})>0$, and hence:

$$
\frac{d \bar{e}}{d \gamma}=\frac{f^{\prime}(\bar{k})}{\mu-\gamma f^{\prime \prime}(\bar{k}) \frac{d \bar{k}}{d \bar{e}}}
$$

is positive. Therefore, both $\bar{k}(\gamma)$ and $\bar{e}(\gamma)$ are increasing in $\gamma$. From this, one infers that the left-hand side of (A.2) is decreasing in $\gamma$. So if the transversality condition holds for $\gamma=\gamma_{1}$ it does also for $\gamma<\gamma_{1}$. Also, the transversality condition is satisfied for $\gamma \in\left(0, \gamma_{\max }\right)$, where the upperbound of the interval is the value of $\gamma$ for which the left-hand side of (A.2) or equivalently of (A.4) becomes nil. The values of $\bar{k}\left(\gamma_{\max }\right)$ and $\bar{e}\left(\gamma_{\max }\right)$ are obtained by solving the system of two equations (A.2) and (A.4) where the inequalities are replaced by equalities.

We now show by contradiction that $\lim _{\gamma \rightarrow 0} \bar{k}(\gamma)=0$. Suppose that it were positive. Then, since $f^{\prime}(\bar{k})>0$ for $\bar{k}>0$, relation $(22)$ would imply that $\lim _{\gamma \rightarrow 0} \varphi(\bar{e}(\gamma))=$ 0 , which in turn implies that $\bar{e}(\gamma)$ and so $\varphi(\bar{e}(\gamma))-\bar{e}(\gamma) \varphi^{\prime}(\bar{e}(\gamma))$ have their limits equal to zero. However, from relation (20) written along the balanced-growth path we infer that $\varphi^{\prime}(\bar{e}(0))=f^{\prime}(\bar{k})\left[f(\bar{k})-\bar{k} f^{\prime}(\bar{k})\right]^{-1}$ would thus be finite. This contradicts our assumption that $\lim _{\bar{e} \rightarrow 0} \varphi^{\prime}(\bar{e})=\infty$. Consequently, $\lim _{\gamma \rightarrow 0} \bar{k}(\gamma)=0$. The same reasoning applies to show that $\lim _{\gamma \rightarrow 0} \bar{e}(\gamma)=0$. If this limit were positive, the limit of $f^{\prime}(\bar{k}(\gamma))$ would be infinite from (22) while it would be finite from (20). 


\section{Appendix B: Proof of Proposition 2}

Given Proposition 1 , since $\bar{k}^{L F}<\bar{k}_{\max }$ by assumption, there is a value $\hat{\gamma}<\gamma_{\max }$ such that $\bar{k}^{*}(\hat{\gamma})=\bar{k}^{L F} ;$ moreover, for $\gamma<\hat{\gamma}, \bar{k}^{*}(\gamma)<\bar{k}^{L F}$ and for $\gamma>\hat{\gamma}, \bar{k}^{*}(\gamma)>\bar{k}^{L F}$.

From (20), we have

$$
\varphi^{\prime}\left(\bar{e}^{*}(\hat{\gamma})\right)<\frac{f^{\prime}\left(\bar{k}^{*}(\hat{\gamma})\right)}{f\left(\bar{k}^{*}(\hat{\gamma})\right)-\bar{k}^{*}(\hat{\gamma}) f^{\prime}\left(\bar{k}^{*}(\hat{\gamma})\right)}=\varphi^{\prime}\left(\bar{e}^{L F}\right)
$$

where the equality comes from $(10),(11)$ and $\bar{k}^{*}(\hat{\gamma})=\bar{k}^{L F}$ by definition of $\hat{\gamma}$. Therefore, we have: $\bar{e}^{L F}<\bar{e}^{*}(\hat{\gamma})$. Since Proposition 1 states that $\bar{e}^{*}$ rises with $\gamma$, it implies that there exists a $\tilde{\gamma}<\hat{\gamma} \operatorname{such}$ that $\bar{e}^{*}(\tilde{\gamma})=\bar{e}^{L F}$. Furthermore, for $\gamma<\tilde{\gamma}$, we have $\bar{e}^{*}(\gamma)<\bar{e}^{L F}$, and for $\gamma>\tilde{\gamma}, \bar{e}^{*}(\gamma)>\bar{e}^{L F}$.

\section{Appendix C: Analytical illustration}

In this analytical example we use the following specification of the key functions:

$$
\begin{aligned}
& u\left(c_{t}, d_{t+1}\right)=\ln c_{t}+\beta \ln d_{t+1}, \\
& \varphi\left(e_{t}\right)=B e_{t}^{\lambda}, \\
& f\left(k_{t}\right)=A k_{t}^{\alpha},
\end{aligned}
$$

with $\beta>0, B>0,0<\lambda<1, A>0$ and $0<\alpha<1$.

Optimality condition (19) along the balanced growth path can then be written as:

$$
\gamma \frac{f^{\prime}\left(\bar{k}^{*}\right)}{1+n}=\varphi\left(\bar{e}^{*}\right)
$$

since (C.1) implies that $u_{d}\left(c_{t-1}^{*}, d_{t}^{*}\right) / u_{d}\left(c_{t}^{*}, d_{t+1}\right)=d_{t+1}^{*} / d_{t}^{*}=\varphi(\bar{e})$ along the balanced growth path. As to optimality condition (20) it yields using (C.4) and (C.2):

$$
w\left(\bar{k}^{*}\right) \varphi^{\prime}\left(\bar{e}^{*}\right)=f^{\prime}\left(\bar{k}^{*}\right)\left[1-\frac{1+n}{f^{\prime}\left(\bar{k}^{*}\right)}\left(\varphi(\bar{e})-\bar{e} \varphi^{\prime}(\bar{e})\right)\right]=f^{\prime}\left(\bar{k}^{*}\right)\left[1-\Delta^{*}\right]
$$

where

$$
\Delta^{*}=\gamma(1-\delta)
$$

From (10), (11) and (C.3) we infer

$$
\frac{w\left(\bar{k}^{*}\right)}{f^{\prime}\left(\bar{k}^{*}\right)}=\frac{1-\alpha}{\alpha \bar{k}^{*}}
$$


which we substitute in (C.5) to obtain

$$
\bar{k}^{*}=\frac{\alpha}{1-\alpha} \frac{1-\Delta^{*}}{\varphi^{\prime}\left(\bar{e}^{*}\right)}=\frac{\alpha}{1-\alpha} \frac{1-\Delta^{*}}{\lambda B}\left(\bar{e}^{*}\right)^{1-\lambda}
$$

where we have also used (C.2). From this expression we obtain by means of (C.4) and (C.3):

$$
\begin{aligned}
\bar{e}^{*} & =\frac{1-\alpha}{\alpha} \frac{\lambda B}{1-\Delta^{*}} \bar{k}^{*}\left(\bar{e}^{*}\right)^{\lambda} \\
& =\frac{1-\alpha}{\alpha} \frac{\lambda}{1-\Delta^{*}} \bar{k}^{*} \varphi\left(\bar{e}^{*}\right) \\
& =(1-\alpha) \frac{\lambda}{1-\Delta^{*}} \frac{\gamma}{1+n} A\left(\bar{k}^{*}\right)^{\alpha}
\end{aligned}
$$

Let us denote by $v^{*}$ the fraction of production used for education along the balanced growth path, that is:

$$
v^{*} \equiv \frac{(1+n) \bar{e}^{*}}{A\left(\bar{k}^{*}\right)^{\alpha}}
$$

We then infer from (C.8):

$$
v^{*}=\gamma(1-\alpha) \frac{\lambda}{1-\Delta^{*}} .
$$

Let us denote by $\bar{C}^{*}$ the aggregate consumption per worker of $h_{t}$ and unit of $h_{t}$ along the balanced growth path:

$$
\begin{aligned}
\bar{C}^{*} & =\frac{1}{h_{t}}\left(c_{t}^{*}+\frac{d_{t}^{*}}{1+n}\right) \\
& =f\left(\bar{k}^{*}\right)-(1+n) \bar{e}^{*}-(1+n) \frac{h_{t+1}^{*}}{h_{t}^{*}} \bar{k}^{*}
\end{aligned}
$$

Since $h_{t+1}^{*} / h_{t}^{*}=\varphi(\bar{e})=\bar{k}^{*} \gamma f^{\prime}\left(\bar{k}^{*}\right)(1+n)^{-1}$ from (C.4), we then obtain using (C.3) and (C.9):

$$
\bar{C}^{*}=A\left(\bar{k}^{*}\right)^{\alpha}(1-v-\gamma \alpha) .
$$

To determine how this aggregate consumption is shared between first- and secondperiod consumptions, let us first remark that along the balanced-growth path, optimality condition (18) yields using (C.1):

$$
f^{\prime}\left(\bar{k}^{*}\right)=\frac{u_{c}\left(c_{t}, d_{t+1}\right)}{u_{d}\left(c_{t}, d_{t+1}\right)}=\frac{d_{t+1}^{*}}{\beta c_{t}^{*}}=\frac{\varphi\left(\bar{e}^{*}\right) \bar{d}^{*}}{\beta \bar{c}^{*}},
$$

with $\bar{c}^{*} \equiv c_{t}^{*} / h_{t}^{*}$ and $\bar{d}^{*} \equiv d_{t} / h_{t}^{*}$. Using (C.4) allows to infer from (C.11):

$$
\frac{\bar{d}^{*}}{\bar{c}^{*}}=\frac{\beta}{\gamma}(1+n)
$$


and therefore

$$
\bar{c}^{*}=\frac{\gamma}{\beta+\gamma} \bar{C}^{*} \text { and } \bar{d}^{*}=\frac{\beta(1+n)}{\beta+\gamma} \bar{C}^{*} .
$$

We also have using (C.4) and (C.9):

$$
\begin{aligned}
\bar{s}(\sigma) \equiv \frac{s_{t}}{h_{t}} & =(1+n) \varphi(\bar{e}) \bar{k}^{*}+(1+n)(1-\sigma) \bar{e}^{*} \\
& =[\gamma \alpha+(1-\sigma) v] A\left(\bar{k}^{*}\right)^{\alpha} .
\end{aligned}
$$

The above results will enable us to obtain an expression for the value of $\bar{T}^{2}$, i.e. the lump-sum tax $T_{t+1}^{2}$ divided by $h_{t}$ that must be levied on retirees for decentralizing the social optimum along the balanced growth path.

From condition $\left(B_{t}\right)$ we have

$$
\bar{T}^{2}(\gamma, \sigma)=T_{t+1}^{2} / h_{t}^{*}=R^{*} \bar{s}^{*}(\sigma)-\varphi\left(\bar{e}^{*}\right) \bar{d}^{*}
$$

which, using the above results in (C.10), (C.13) and (C.14), can be rewritten as:

$$
\bar{T}^{2}(\gamma, \sigma)=R^{*} A\left(\bar{k}^{*}\right)^{\alpha} \gamma \psi(\gamma, \sigma)
$$

with

$$
\psi(\gamma, \sigma) \equiv \alpha+\frac{(1-\sigma)(1-\alpha) \lambda}{1-\gamma(1-\lambda)}-\frac{\beta}{\beta+\gamma}+\frac{\beta \gamma}{\beta+\gamma}\left(\alpha+\frac{(1-\alpha) \lambda}{1-\gamma(1-\lambda)}\right) .
$$

It is easily verified that $d \psi / d \gamma>0,0 \leq \gamma \leq 1$. We also have $\psi(0, \sigma)=\alpha+$ $(1-\sigma)(1-\alpha) \lambda-1<0$ iff $\sigma>-(1-\lambda) \lambda^{-1}$ and $\psi(1, \sigma)=\alpha+(1-\sigma)(1-\alpha)>0$. Therefore, iff $\sigma>-(1-\lambda) \lambda^{-1}$, there exists a unique value $0<\overline{\bar{\gamma}}(\sigma)<1$ such that $\bar{T}^{2}(\gamma, \sigma)<0$ for $\gamma<\overline{\bar{\gamma}}(\sigma)$ and $\bar{T}^{2}(\sigma)>0$ for $\gamma>\overline{\bar{\gamma}}(\sigma)$; otherwise $\bar{T}^{2}(\gamma, \sigma)$ is positive for anly $0<\gamma<1$. On the other hand, $\bar{T}^{2}$ falls when $\sigma$ rises.

Likewise, an expression for $\bar{T}^{1}$ can be found. Using condition $\left(C_{t}\right)$ we infer from condition $\left(A_{t}\right)$ :

$$
\bar{T}^{1} \equiv \frac{T_{t}^{1}}{h_{t}}=\left[w^{*}-R^{*} \frac{\bar{e}^{*}}{\varphi\left(\bar{e}^{*}\right)}\left(1-\Delta^{*}\right)\right]-\bar{c}^{*}-\bar{s}^{*}(\sigma)
$$

Substituting from (C.7), (C.13) and (C.14) this expression can then be written as:

$$
\begin{aligned}
\bar{T}^{1}(\gamma, \sigma)= & \{(1-\alpha)(1-\lambda) \\
& \left.-\frac{\gamma}{\beta+\gamma}[1-\sigma v+\beta(\gamma \alpha+(1-\sigma) v)]\right\} A\left(\bar{k}^{*}\right)^{\alpha}
\end{aligned}
$$

The derivative of $\bar{T}^{1}$ with respect to $\gamma$ is of ambiguous sign while those with respect to $\sigma$ is positive. 
Département des Sciences Économiques de l'Université catholique de Louvain

Institut de Recherches Économiques et Sociales

Place Montesquieu, 3

1348 Louvain-la-Neuve, Belgique 